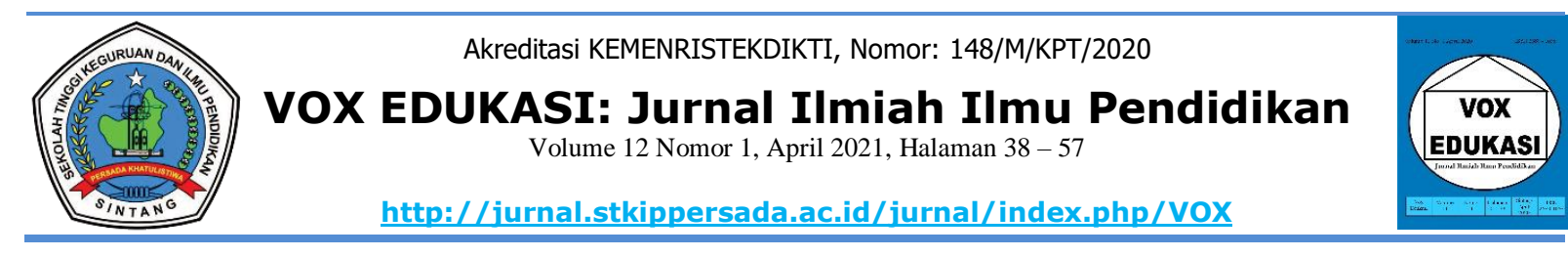

\title{
OPTIMALISASI GURU DALAM MENUMBUHKAN MINAT MEMBACA HURUF BRAILLE PADA SISWA TUNANETRA
}

\author{
Muhamad Arif ${ }^{1}$, Mei Kalimatusyaroh ${ }^{2}$, Nur Rahayu Setyawati ${ }^{3}$ \\ 1,3 STAI Al-Azhar Menganti. Gresik, 61174, Indonesia. \\ ${ }^{2}$ IAI Al-Khoziny Buduran. Sidoarjo, 61252, Indonesia. \\ Email:muhamadarif070593@gmail.com ${ }^{1}$, fasya.aazzahro@gmail.com ${ }^{2}$,nurrh29@gmail.com ${ }^{3}$
}

\section{INFO ARTIKEL \\ Riwayat Artikel: \\ Menerima : 11 Januari 2021 \\ Revisi : 29 Maret 2021 \\ Diterima : 08 April 2021}

\section{Kata Kunci:}

Guru, Tunanetra, Media

Belajar

\section{Keywords:}

Teacher, Blind, Learning

Media

\section{Korespondensi:}

\section{Muhamad Arif}

STAI Al-Azhar Menganti Gresik

Email:

muhamadarif070593@gmail.com

\begin{abstract}
ABSTRAK
Pendidikan menjadi hak dari setiap warga negara sebagaimana amanat Undangundang Dasar 1945, Pasal 31 Ayat 1, sejalan dengan amanat di atas pendidikan untuk anak kebutuhan khusus juga di berlakukan di negara Indonesia, maka diperlukan sebuah proses pembelajaran yang maksimal mulai dari sumberdaya manusianya yaitu guru. tujuan penelitian ini adalah tentang bagaimana optimalisasi guru dalam menumbuhkan minat membaca huruf braille pada siswa tunanetra. Apa saja media yang di gunakan guru dalam menumbuhkan minat membaca huruf braille pada siswa tunanetra, serta apa saja kendala guru dalam menumbuhkan minat membaca huruf braille pada siswa tunanetra. Penelitian dilakukan pada Sekolah Luar Biasa Cerme Gresik, melalui riset kualitatif dengan pendekatan studi kasus, sumber data primer dalam penelitian ini adalah guru pengajar siswa tunanetra, analisis data yang di pakai adalah analisis data Miles dan Huberman dengan perpaduan Triangulasi data. Hasil penelitian menunjukkan optimalisasi penumbuhan minat membaca huruf braille yang di lakukan guru, dengan memperkuat proses pembelajaran mulai dari perencanaan, pelaksanaan dan evaluasi belajar membaca, selain itu beberapa media pembelajaran yang digunakan seperti, braille kasar, halus, peta braille dan beberapa media lainnya. Terlepas dari beberapa media di atas masih ditemukannya kendala dalam penumbuhan minat membaca huruf braille, seperti naik turunya motivasi pada diri siswa, IQ siswa tunanetra yang cenderung rendah dari pada siswa normal, perlunya peningkatan kompetensi pada guru tunanetra, serta perlu adanya media pembelajaran yang sesuai kebutuhan siswa, seperti buku pelajaran braille.
\end{abstract}

\section{ABSTRACT}

Education is the right of every citizen as mandated by the 1945 Constitution, Article 31 Paragraph 1, in line with the above mandate that education for children with special needs is also implemented in the state of Indonesia, so a maximum learning process is needed starting from human resources, namely teachers. . so in this study discusses how to optimize the teacher in fostering interest in reading Braille in blind students. What media are used by the teacher in fostering interest in reading braille in blind students, as well as what are the obstacles for teachers in growing interest in reading braille in blind students. The research was conducted at the Cerme Gresik Special School, through qualitative research with a case study approach, the primary data source in this study was teachers of blind students, the data analysis used was data analysis by Miles and Huberman with a combination of data triangulation. The results showed the optimization of the growth of interest in reading braille by the teacher, by strengthening the learning process starting from planning, implementing and evaluating learning to read, besides that some learning media were used, such as coarse, fine braille, braille maps and several other media. Apart from some of the media above, there are still obstacles in growing interest in reading braille, such as the ups and downs of motivation in students, the IQ of blind students who tend to be lower than normal students, the need to increase competence in blind teachers, and the need for learning media that suits their needs. students, such as braille textbooks. 


\section{PENDAHULUAN}

Perkembangan di era revolusi industri 4.0. memberikan efek percepatan dari semua lini, mulai dari pendidikan, ekonomi, ketahanan negara dan beberapa perkembangan lainnya. termasuk menjadikan seluruh negara di dunia saling berpacu baik secara kuantitas dan kualitas. Sebagaimana keberadaan Negara Indonesia yang secara demografi menjadi salah satu dari empat negara dunia dengan jumlah penduduk terbesar di dunia. Indonesia berada di bawah Republik Rayat Cina (RRC), India dan Amerika. Sedangkan dalam penerapan sistem demokrasi indonesia menempati urutan ketiga dunia, di bawah amerika dan india.(Ali, 2009). Namun, perkembangan pendidikan negara indonesia, mempunyai catatan dengan segudang perbaikan, sebagaimana yang dilansir oleh situs "BBC News" yang di rilis Programme for international Student Assement (PISA) Prancis, menjelaskan bahwa negara indonesia mendapatkan peringkat ke-72 dari 77 negara dunia, masih di bawah negara tetangga yaitu: malaysia, brunei darussalam dan singapura yang menempati peringkat kedua. PISA menerbitkan hasil servey melalui tiga kriteria, yaitu membaca, matematika dan pengetahuan (science).(Peringkat pendidikan Indonesia di bawah Malaysia, China yang terbaik di dunia, 2019). Sebuah percepatan perbaikan dalam memasuki era revolusi industri 4.0. sudah selayaknya di lakukan oleh negara indonesia dengan mengikuti perkembangannya, terutama dalam dunia pendidikan.
Pembahasan tentang pendidikan di indonesia maka sangatlah variatif, Ahmad Darlis dalam penelitiannya menjelaskan pendidikan di indonesia terbagi menjadi tiga, yaitu pertama, pendidikan informal, di atur dalam Undang-undang sistem pendidikan nasional No, 20 tahun 2003 pasal 1 ayat 13 yang membahsan tentang sentral dari pendidikan informal yaitu keluarga dan lingkungan sekitar. Kedua, pendidikan non formal menjadi sebuah pendidikan yang berada di luar pendidikan formal, namun mempunyai jenjang yang jelas, tertib dan terencana. Seperti keberadaan pendidikan diniyah, malis taklim, diniyah takmiliyah yang di atur oleh peraturan pemerintah no 55 tahun 2007 pasal 21 ayat 1. Sedangkan, ketiga dalah pendidikan formal, sebuah pendidikan yang di dalamnya diatur secara terstruktur, terukur dan berjenjang, mulai dari pendidikan dasar, pendidikan menengah hingga pendidikan tinggi. Seperti jenjang SD/MI, SMP/MTs, SMA/SMK/MA dan Perguruan Tinggi.(Darlis, 2017)

Pada pendidikan formal sebagaimana yang telah di atur dalam peraturan pemerintah juga terdapat catatan, yaitu adanya penyetaraan berupa pendidikan formal untuk peserta didik kelainan dan kecerdasan atau bakat istimewa (pendidikan inklusi). Sebagaimana riset dari Ery Wati, yaitu adanya manejemen yang baik pada pendidikan dasar negeri 32 di kota aceh dalam menyelenggaraan pendidian anak berkelainan atau lebih familiar dengan sebutan pendidikan inklusi, hal 
tersebut tidak menyalahi aturan pemerintah, karena dalam Peraturan pendidikan nasional RI No.70 Tahun 2009 pasal 1, tentang sistem penyelenggaraan pendidikan dengan memberikan porsi yang sama kepada peserta didik yang mempunyai kelainan dan kecerdasan atau bakat istimewa untuk mengikuti pembelajaran bersama peserta didik pada umunya. (Wati, 2014).

Pendidikan inklusi terklasifikasi menjadi beberapa bagian, sebagaimana pemaparan hasil penelitian Suderajat, Bidari dan Amalia, menjelaskan bahwa pendidikan inklusi di SDN Muhammadiyah 3 Cirebon, dalam proses pembelajaran terbagi menjadi tujuh bagian, yaitu: tunanetra, tunarungu, tunagrahita, tunalaras, tunadaksa, slowlearner dan anak berbakat. Keadaan tunanetra menjadi sebuah catatan tersendiri dalam proses pembelajaran, karena keadaan seseorang yang mengalami gangguan dalam pengelihatan baik secara total maupun lemah (low vision), salah satu media yang dapat membantu dalam proses pembelajaran adalah dengan menggunakan media braille.(Suderajat et al., 2018). Pentingnya pendidikan untuk tunanetra juga di sampaikan oleh Chiu dalam risetnya tentang awal mula berdirinya lembaga pendidikan yang didirikan oleh minoritas penyandang tunanetra di Taiwan sekitar tahun 1870 hingga 1970-an, dengan berkembangnya waktu pendidikan untuk tunanetra menjadi sebuah kebutuhan.(Chiu, 2014). Keberadaan di atas diperkuat dengan beberapa hasil riset pendidikan inklusi yang terfokus pada penyandang tunanetra dengan media braille.
Rudiyati dalam risetnya yang berjudul pembelajaran membaca dan menulis braille pemula bagi anak tunanetra di SLB-A Yaketunis Yogyakarta, memaparkan bahwa pembelajaran membaca dan menulis dengan media braille sangat di butuhkan bagi penyandang tunanetra. Dalam pembelajaran braille yang di utamakan adalah mempelajari titik braille terlebih dahulu, setelah siswa memahami titik braille, maka guru mengarhkan siswa kepada mesin ketik braille. Jadi, yang pertama di ajarkan adalah proses belajar menghafal titik braille agar dapat membaca secara tepat, setelah siswa dapat membaca barulah siswa di ajarkan untuk menulis braille. Namun, yang menjadi catatan besar Rudiyati, adalah peran guru yang mengajarkan membaca dan menulis braille mempunyai peran yang sangat penting dalam proses belajar mengajar. Karena bagi tunanetra braille menjadi alat komunikasi dan mengakses informasi, beberapa media yang di gunakan mulai dari pemanfaatan limbah kain, dan di padukan dengan biji-bijian. Selain itu juga menggunakan media reken Plank, reglet untuk menulis dan stylus .(Rudiyati, 2010)

Sejalan dengan hasil riset dari Iswara, Sumpeno dan Purnomo, yang mencoba menyederhanakan dalam proses membaca pemula bagi tunanetra dengan menggunakan aplikasi metode chain epproxmation, salah satu metode yang terbilang berhasil menggunakan scan camera webcame dengan akurasi $84 \%$ akurat dalam mengenal huruf braille.(Iswara et al., 2013) Selain itu terdapat hasil penelitian Assyifa, tentang pentingnya 
membaca pada siswa tunanetra di sekolah luar biasa Negeri 1 Bantul, hasil penelitian menunjukkan bahwa, guru di SDN 1 Bantul dalam proses implementasi pra membaca pada siswa tunanetra, dibantu dengan menggunakan beberapa media, seperti Barailelatex, buku konsep memahami garis tegak dan datar, balok braille, geometri dan manik-manik. Dengan beberapa media tersebutlah guru dapat memaksimalkan program pra membaca bagi siswa tunanetra (Assyifa, 2019).

Sebagaimana, beberapa hasil penelitian di atas, Isnani dalam penelitiannya juga menjelaskan bahwa dalam meningkatkan kemampuan membaca tulisan braille pada siswa tunanetra salah satunya dengan menggunakan sistem menggold, hasil penelitian menunjukkan bahwa terkait kemampuan membaca siswa tunanetra masih sangat variatif, meskipun di berikan perlakuan yang sama, namun masih terdapat beberapa siswa yang memerlukan pendampingan yang intens dalam hal membaca bagi tunanetra. Maka, peran seorang guru secara maksimal yang sangat diperlukan oleh siswa tunanetra dalam belajar membaca huruf braille.(Isnaini, 2013) peran braille pada siswa tunanetra sangatlah penting hal tersebut diungkapkan oleh Hoshino, Kiyosawa dan Otake, bahwa keberadaan pembelajaran braille harus di tanamkan pada diri siswa tunanetra, karena braille menjadi satu-satunya media peraba untuk belajar siswa tunanetra dalam mengenal huruf dan angka.(Hoshino et al., 2000)
Dari beberapa hasil penelitian di atas terdapat salah satu ruang yang perlu dilakukannya penelitian secara mendalam, tentang optimalisasi guru dalam menumbuhkan minat membaca huruf braille pada siswa tunanetra. Karena keberhasilan siswa tunanetra Karena sedari awal guru harus mengenalkan titik-titik dari huruf braille hingga menulis braille. Maka, berdasarkan analisa di atas, peneliti ingin melakukan penelititian secara spesifik tentang optimalisasi guru dalam menumbuhkan minat membaca bagi siswa tunanetra di salah satu lembaga pendidikan dasar negeri, yaitu pada sekolah luar biasa (SDLB) Negeri Cerme Gresik, salah satu sekolah dasar luar biasa yang sangat direkomendasikan oleh pemerintah kabupaten gresik.(Daftar Sekolah Luar Biasa (SLB) Recommended Di Gresik, 2017) Rekomendasi tersebut bukan tanpa alasan, karena sekolah luar biasa (SLB) Negeri Cerme sudah banyak mendapatkan prestasi ademik dan non akedemik. Selain itu keadaan optimalisasi yang dilakukan guru dalam mengawal belajar membaca huruf braille pemula siswa tunanetra sangatlah efektif, sehingga minat membaca siswa tunanetra lebih besar di banding siswa $\mathrm{ABK}$ lainnya meskipun banyak keterbatasan. Maka, peneliti mengerucutkan pada judul optimalisasi guru dalam menumbuhkan minat membaca huruf braille pada siswa tunanetra di Sekolah Luar Biasa Negeri Cerme Gresik. Dalam penelitian ini terdapat tiga fokus penelitian, pertama tentang bagaimana optimalisasi guru dalam menumbuhkan minat 
membaca huruf braille pada siswa tunanetra. Kedua, apa saja media yang di gunakan guru dalam menumbuhkan minat membaca huruf braille pada siswa tunanetra. Dan ketiga, adalah apa saja kendala guru dalam menumbuhkan minat membaca huruf braille pada siswa tunanetra.

\section{METODE PENELITIAN}

Pada penelitian ini peneliti menggunakan metode penelitian kualitatif, dengan pendekatan studi kasus sebagaimana yang di sampaikan K Yin, bahwa studi kasus adalah sebuah pendekatan penelitian dengan melihat latar kejadian secara alamiah (Arif \& Sulistianah, 2019) Sebuah keadaan pengoptimalisasian guru dalam menumbuhkan minat membaca huruf braille pada siswa tunanetra di Sekolah Luar Biasa Negeri Cerme Gresik. Penelitian ini dilaksanakan selama 4 bulan di mulai dari bulan September sampai Desember 2020. Sumber data penelitian ini terbagi menjadi dua, sumber data primer, meliputi; guru kelas, guru pengajar huruf braille dan kepada sekolah. Sedangkan sumber data sekunder pada penelitian ini meliputi seluruh elemen sekolah yang mempunyai hubungan secara langsung dengan pihak sekolah. Sedangkan Metode pengumpulan data pada penelitian menggunakan metode observasi non partisipatif, wawancara semi terstruktur dengan memfokuskan pada tiga focus masalah awal, bagaimana optimalisasi guru dalam menumbuhkan minat membaca huruf braille pada siswa tunanetra? apa saja media yang di gunakan guru dalam menumbuhkan minat membaca huruf braille pada siswa tunanetra? Serta apa saja kendala guru dalam menumbuhkan minat membaca huruf braille pada siswa tunanetra? Selain itu peneliti menggunakan media dokumentasi. Analisis data pada penelitian adalah analisis data dari Miles and Hubarman, dengan tiga strata yaitu, data kondensasi, data display dan kesimpulan.(Arif \& Kalimatusyaro, 2020) Sedangkan uji keabsahan data pada penelitian ini menggunakan Triangulasi data, meliputi triangulasi metode yaitu proses uji keabsahan data dengan menggunakan metode yang sama dengan sumber yang berbeda, triangulasi sumber, adalah proses uji keabsahan data dengan menggunakan sumber sama. Namun, dengan metode berbeda dan triangulasi teori, adalah proses triangulasi dengan memadukan dari hasil teori yang ada atau dengan menggunakan hasil riset sebelumnya.

\section{HASIL DAN PEMBAHASAN}

Hasil

Optimaliasi Guru dalam Menumbuhkan Minat Membaca Huruf Braille Siswa Tunanetra

Keberadaan optimalisasi guru dalam menumbuhkan minat membaca siswa tunanetra di SDLB Cerme Gresik sangatlah penting. Karena, terlebih dahulu guru harus memberikan pembelajaran kepada siswa tuna netra dalam menggunakan huruf braille. Implementasi proses pembelajaran membaca menggunakan huruf braille dimulai dari tiga tahapan: 1) tahap perencanaan, 2) pelaksanaan, dan 3) evaluasi pembelajaran. 
Sebagaimana yang di sampaikan oleh ED, bahwa proses perencanaan dalam pembelajaran membaca pada anak tunanetra, adalah titik awal penumbuhan minat membaca hurf braille siswa tunanetra. Karena guru harus menyiapkan perangkat pembelajaran yang maksimal seperti RPP, model pembelajaran dan media pembelajaran yang dapat menstimulus siswa. seperti buku dongeng abu nawas, 1001 malam. Selain itu siswa tunanetra mempunyai kewajiban untuk menghafalkan titik braille dan abjad secara lacar agar dapat membaca tanpa hambatan. Selain itu guru juga memaksimalkan media sosial, seperti whatsapp untuk mengirimkan rekaman potongan dari sandi huruf braille. Sedangkan dalam proses pelaksanaan, para guru mengoptimalkan siswa tunanetra dengan metode ceramah, demonstrasi dan praktik agar dapat menumbuhkan minat membaca dengan melatih belajar meraba huruf braille menggunakan media papan braille serta reglet dan stilus. Setelah mereka cukup memahami huruf braille tahapan selajutnya guru mengenalankan media braille tex. Selain itu dalam mengoptimalkan penumbuhan minat membaca huruf braille, guru menuliskan beberapa kalimat yang di sukai oleh siswa tunanetra, setelah itu siswa bergantian menirukan. Sedangkan untuk siswa yang sudah lancar membaca, siswa dilatih untuk membaca cerita setelah itu menyimpulkan. Sedangkan dalam tahap melakukan evaluasi pada pembelajaran membaca para guru, mempunyai beberapa model, seperti guru melakukan wawancara secara face to face pada siswa tunanetra dengan menanyakan kesulitan yang di alaminya. Selain itu guru dapat mengevaluasi dengan siswa menulis setelah itu siswa membaca satu persatu kepada guru dari yang sudah di tuliskan. Namun, yang perlu di berikan catatan adalah ketika guru memberikan pembelajaran membaca braille, guru harus terus memberikan motivasi kepada siswa tunanetra, karena dengan motivasilah siswa akan dapat terus belajar membaca braille, sehingga tumbuh minat membaca dari dirinya sendiri.

$$
\text { Optimalisasi guru dalam }
$$
menumbuhkan minat membaca huruf braille pada siswa tunanetra bukan pekerjaan yang mudah. Karena pekerjaan penumbuhan minat pada siswa tunanetra jauh lebih sulit dibandingkan kepada siswa normal. Hal tersebut di benarkan oleh IS salah satu guru di Sekolah Dasar Luar Biasa, tentang optimalisasi yang di lakukan dalam proses pembelajaran huruf braille. Meliputi tiga tahapan, yaitu: pertama tahap perencanaaan, yang di mulai dari guru harus menyiapkan perangkat pembelajaran secara serius mulai dari metode, sampai media yang di gunakan. Karena pada tunanetra buku ajar jarang di temukan yang sudah menggunkan huruf braille, karena lebih banyak seperti bukunya siswa normal. Kedua, tahap pelaksanaan pembelajaran tahap pertama adalah guru menggunakan metode demonstrasi dan ceramah contoh guru memberikan pengenalanpengenalan pada sekitar, seperti pengenalan nama ayah, ibu, kakak dan dirinya sendiri, setelah itu guru memberikan metode 
menghafal terutama menghafal huruf abjad AZ. Selain itu dalam proses membaca pada siswa tunanetra seharusnya dimulai dari katakata yang mereka sukai, seperti contoh: siswa suka kata "kenalpot brong" dari kata-kata tersebut siswa semakin paham dengan huruf A sampai Z. Ketiga, adalah proses evaluasi pembelajaran dalam hal ini guru melakukan dengan berbincang langsung kepada siswa tunanetra. Selain itu siswa di tagih untuk melakukan setoran kepada guru dan mengulangya di setiap pertemuan. Selain itu guru memberikan kartu huruf sebanyak 3 kartu dan siswa menjawab, jika benar dalam menjawab dapat di pastikan siswa sudah hafal huruf tersebut. Pada tahap evaluasi guru di haruskan sebaik mungkin memberikan motivasi kepada siswa.

Beberapa proses pembelajaran huruf braille secara bertahap dan dilakukan secara terus menerus, akan menimbulkan terjadinya penumbuhan minat membaca pada siswa tunanetra secara maksimal. Seperti yang di sampaikan oleh WK sebagai salah satu guru di Sekolah Dasar Luar Biasa, juga menyampaikan bahwa proses penumbuhan minat membaca harus dimulai dengan proses pembelajaran membaca yang benar. Mulai dari perancanaan guru di haruskan untuk mempersiapkan perangkat pembelajaran secara maksimal terutama dalam hal media pembelajaran harus dapat di maksimalkan, seperti braille tex, regket, stilus dan buku dongeng dari huruf braille. Sedangkan dalam proses pelaksanaan pembelajaran guru di haruskan untuk lebih kreatif dalam melakukan proses pembelajaran, beberapa metode yang sering digunakan adalah demonstrasi, tanya jawab dan ceramah. selain guru mewajibkan siswa untuk menghafalkan abjad A-Z. Pembelajaran menggunakan media braille tex, dan media replika seperti masjid, candi dan hewan-hewan agar siswa lebih faham. Selain itu dalam pembelajaran siswa di berikan materi menulis dengan menggunakan reglet dan stilus setelah itu siswa membaca apa yang sudah di tulis. Dalam hal evaluasi pembelajaran guru meggunakan beberapa cara: seperti guru melontarkan pertanyaan tentang huruf yang sudah di hafal oleh siswa, selain itu guru di haruskan mengevaluasi cara siswa meraba huruf braille yaitu dengan observasi secara langsung kepada masing-masing siswa.

Pemaparan di atas juga di rasakan oleh seluruh siswa tunanetra, tentang bagaimana masih perlunya berlatih meraba sampai menyambung dari satu kata menjadi kalimat pada huruf braille. Maka di sinilah peran guru sangat di harapkan mengawal secara intensif, terutama dalam proses belajar mengajar. Siswa tunanetra tergolongan sangat minim buku bacaannya, karena buku belajarpun mereka justru mendapatkan buku belajar layaknya siswa normal. Sedangkan buku yang menggunakan huruf braille sangatlah terbatas. Namun, pihak sekolah dan para guru terus mengusahkan memberbanyak buku literasi dengan huruf braille. Maka, berdasarkan hasil wawancara, observasi dan kumpulan doumentasi yang di dapatan oleh peneliti dapat di ambil benang merah, bahwa minat membaca huruf braille pada siswa tunanetra 
tidak akan pernah ditemukan. Jika, para guru tidak mengoptimalkan proses pembelajaran, karena hanya melalui pembelajarlah siswa akan dapat menumbuhkan minat membaca huruf braille.

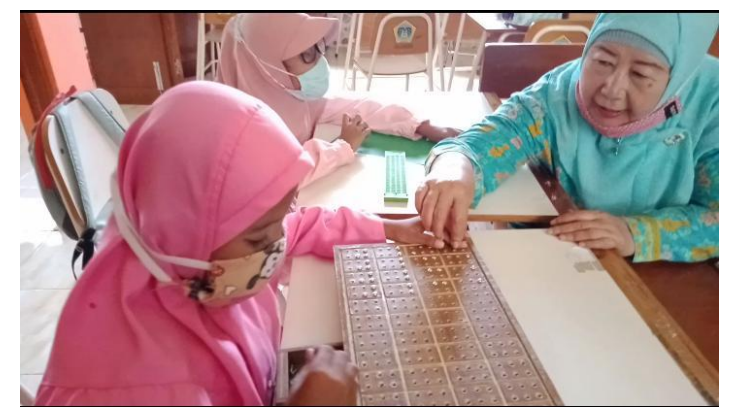

Gambar 1: Proses Pembelajaran dengan Media Braille Kasar

Beberapa cara yang sudah di lakukan oleh para guru di SDLB Cerme Gresik dalam mengoptimalkan pembelajaran melalui tiga tahapan. Pertama, tahap perencanaan: para guru di haruskan menyiapkan perangkat pembelajaran secara tepat, mulai dari Rencana Pelaksanaan Pembelajaran yang di dalamnya terdapat model pembelajaran yang tepat pada siswa tunanetra dan media pembelajaran yang di sukai oleh siswa tunanetra. Kedua, tahap pelaksanaan, dalam tahap pelaksanaan para guru menggunakan beberapa metode seperti, 1) metode menghafal untuk siswa tunanetra dalam mengenali huruf abjad, yaitu dengan menghafal abjad dari A-Z. 2) metode ceramah, yaitu guru memeberikan materi dengan bercerita serta menjelaskan titik-titik pada huruf braille 2) metode tanya jawab, huruf abjad di gunakan untuk melihat perkembangan siswa dalam menghafal abjad dari A sampai Z. 3) metode latihan seperti pembelajaran meraba siswa yang sudah mahir, di berikan materi menulis dengan menggunakan reglet dan stilus. Karena dengan menulis siswa nantinya dapat pelajaran membaca dari yang sudah di tulis, sebagaimana arahan yang sudah di berian oleh guru. 4) metode demonstrasi digunakan guru kepada siswa untuk di ajarkan menggunakan papan kayu braille agar dapat mengetahui titik-titik (kode) pada setip huruf abjad. Setelah papan kayu braille siswa di berikan pembelajaran tentang braille tekx kasar dan taha akhir menggunakan braille teks halus. Tahap ketiga adalah tahap evaluasi pembelajaran. Para guru mempunyai cara yang hampir sama, yaitu guru melakukan observasi secara langsung kepada masing-masing siswa dalam proses pembelajaran memahami huruf braille menggunakan media braille. Selain itu guru melakukan interview kepada masingmasing siswa tentang perkembangan pemahaman huruf braille ketika membaca dan evaluasi yang dilakukan selain dua hal di atas adalah dengan menggunakan kartu huruf braille, yaitu, dengan guru memberikan 3 kartu huruf, siswa meraba dan siswa menjawab kartu hurufnya.

\section{Media Belajar Guru dalam Menumbuhkan Minat Membaca Huruf Braille Siswa Tunanetra \\ Media pembelajaran menjadi salah} satu kunci dalam mensukseskan pembelajaran, terutama pembelajaran pada anak tunanetra, melihat peran yang cukup signifikan, maka seorang guru di haruskan mampu memaksimalkan keberadaan media dengan sebaik mungkin. Beberapa media pembelajaran di adakan dan selalu diperbaruai sesuai dengan tantangan yang berkembang dengan tujuan siswa tunanetra mampu 
mengimplementasikan media untuk belajar secara maksimal sehingga dapat menumbuhkan minat membaca pada siswa. hal tersebut juga di sampaian oleh ED sebagai guru yang setiap hari menemani siswa tunanetra dalam proses belajar membaca huruf braille. Beberapa media yang di gunakan adalah, papan braille kayu untuk belajar braille bagi pemula, setelah itu siswa di kenalkan dengan braile tex, setelah siswa sudah memahami tatacara penggunaan braille kasar, setelah siswa mahir menggunakan braille kasar. Maka siswa di berikan pembelajaran tentang braille tex. Braille tex menjadi pembelajaran di akhir karena braille tex tinggal menekan tombol. Selain media tersebut beberapa medaia yang digunakan dalam pembelajaran adalah globe braille, peta braille, meteran braille, buku tematik (masih banyak yang belum braille), majalah braille dan buku cerita braille yang menjadi buku kesukaan para tunanetra selain mereka mendengarkan cerita dari hasil rekaman, seperti yang terdapat di youtube dan media sosial lainnya sedangkan dalam tulis menulis siswa tunenetra menggunakan media reglet dan stilus. Karena keterbatasan tunanetra hanya pada melihat.

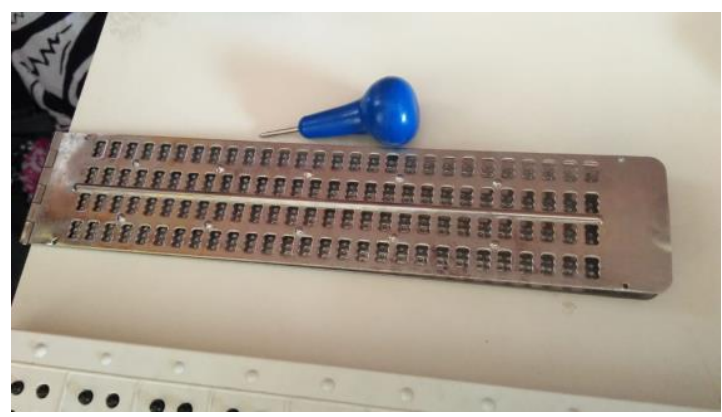

Gambar 2: Media Reglet dan Stilus
Dari pemaparan di atas, maka keberadaan media memang menjadi salah satu kesuksesan dalam menumbuhkan minat membaca siswa tunanetra. Hal tersebut juga di sampaikan oleh IS selaku guru siswa tunanetra. IS menjelaskan bahwa dalam proses belalajr mengajar anak tunanetra terutama dalam menumbuhkan minat membaca pada siswa. maka guru mempunyai kewajiban agar benar-benar menyiapkan media pembelajaran sebaik mungkin, karena dengan menggunakan media yang tepatlah siswa kan mudah memahami huruf braille. Sebagaimana yang sudah berjalan IS dalam pembelajaran menggunakan media papan braille khusus para pemula yang sebelumnya tidak mengetahui apa itu huruf braille?, selain itu media kartu braille juga menjadi pilihan yang tepat agar siswa hafal dengan titik yang ada pada masing-masing huruf. Selain itu media yang di gunakan adalah media braille kasar dan braille tex, yang semuanya bersifat meraba, selain itu juga terdapat buku cerita seperti cerita dongeng 1001 malam, majalah braille. Sedangkan dalam menghafal huruf abjad media yang digunakan adalah tape recorder dengan berisikan bunyi dari masing-masing huruf abjad, selain itu menggunaan audio box. Namun, dengan beberapa media di atas yang mempunyai perannya cukup signifikan dalam pembelajran siswa tunanetra akan mengalami kegagalan. Jika, tidak di dukung peran guru secara maksimal dalam memanfaakan media pembelajaran pada proses penumbuhan minat membaca huruf braille pada siswa tunanetra. Selain media di atas dalam menulis para guru 
memberikan media reglet, stilus dan buku tebal untuk melubangi sebagai cara awal siswa tunanetra menulis huruf braille.

Sebagaimana pemaparan hasil wawancara di atas, WK juga menjelaskan tentang beberapa media yang digunakan dalam proses pembelajaran, seperti papan braille sebagai salah satu papan raba yang di gunakan guru untuk memberikan pelajaran huruf braille, setelah itu menggunakan braille kasar agar siswa lebih faham tentang titik-titik yang terdapat pada setiap huruf abjad braille. Sedangkan braille tex di gunakan bagi siswa yang sudah mahir dalam proses meraba, karena proses berkerjanya media braille tex hanya dengan menekan sebuah tombol. Dalam menghafal huruf abjad, media yang di gunakan adalah audio box dan media sosial seperti whats app untuk dikirim recorder huruf abjad. Sedangkan dalam menulis guru memberikan media reglet, Stilus dan buku tebal untuk di lubangi. Selain itu media yang digunakan adalah buku ajar, majalah braille, buku cerita braille, peta braile, globe braille.

Berdasarkan dari beberapa hasil di atas, maka dapat di ambil sebuah garis lurus bahwa pemilihan media belajar bagi siswa tunanetra sangatlah penting, dengan disertai kompetensi guru yang maksimal. Beberapa media belajar yang digunakan sesuai dengan kebutuhan dalam proses menumbuhkan minat membaca siswa tunanetra. Pertama, dalam hal menghafal huruf braille media yang digunakan oleh guru adalah media audio box dan pemanfaatan media sosial whatsapp untuk mengirimkan recorder abjad. Kedua, media yang digunakan dalam mengasah hafalan siswa tunanetra, yaitu dengan mengguanakan papan braille, setelah faham beralih ke papan braille kasar, setelah siswa faham titik secara lancar maka siswa diberikan materi braille tex, selain media di atas guru juga merangsang otak siswa agar minat membacanya tumbuh yaitu dengan menggunakan media, seperti majalah braille, cerita dongeng braille, peta braille, golebe braille dan buku pelajaran (masih belum braille). Ketiga, media pendukung membaca selanjutnya adalah reglet, stilus dan kertas tebal, media ini digunakan untuk menulis awal siswa. karena dari tulisan inilah siswa akan belajar membaca perhuruf, perkata hingga perkalimat.

\section{Kendala Guru dalam Menumbuhkan Minat Membaca Huruf Braille Siswa Tunanetra} Pemaparan tentang proses pembelajaran untuk tunanetra sudah nampak jelas di atas, disertai dengan media yang digunakan. Namun, dalam proses pembelajaran tidak menutup kemungkinan terjadinya beberapa kendala yang di alami oleh para guru. Hal tersebut di sampaikan oleh ED tentang beberapa kendala dalam proses penumbuhan minat membaca siswa tunatra, meliputi: 1) keberadaan siswa tunanetra yang lebih aktif dan cenderung sulit untuk di kondisikan ketika dalam proses pembelajaran huruf braille. Pada kendala tersebut guru di dorong untuk terus mendekati siswa dan guru di dorong untuk terus memberikan motiasi kepada siswa tunanetra 2) kurangnya buku pelajaran dengan huruf braille, karena yang diberikan kepada sekolah adalah buku 
pelajaran seperti buku siswa normal. 3) untuk media pembelajaran seperti papan braille, braille tex dan braille kasar perlu untuk di tambahkan. 4) rendahnya IQ pada siswa tunanetra, karena keterbatasan dalam belajar. 5) adanya siswa yang mempunyai keterbatasan ganda, seperti salah satu siswa mempunyai keterbatasan tunanetra dan tunagrahita.

Keberadaan kendala dalam proses penumbuhan minat membaca huruf braille juga di temui oleh IS, beberapa kendala yang di temui seperti: 1) kurangnya buku belajar dengan menggunakan huruf braille, hal ini menimbulkan siswa hanya dapat memahami melalui pendengaran yang di sampaikan oleh guru. 2) perlunya penambahan media pembelajaran seperti braille tex, papan braille serta reglet dan stilus. Jika memang sekarang berbasis teknologi sanat memungkinkan pembelajaran dengan menggunakan teknologi khusus siswa tunanetra. 3) keterbatasan IQ menjadi salah satu kendala yang tidak bisa di tolak, karena posisi mereka sanagat jarang mendapatkan pengetahuan baru, di tambah beberapa siswa yang tertutup serta cenderung pendiam. Maka, guru harus ekstra sabar dalam melakukan proses belajar membaca.

Kendala dalam proses belajar dengan tujuan agar siswa dapat tumbuh minat membaca huruf braille, juga disampaikan oleh WK selaku guru pada siswa tunanetra di SDLB Cerme Gresik, beliau menjelaskan tentang beberapa kendala yang di hadapi seperti: 1) siswa yang masih minim pengetahuan di karena keterbatasannya dalam melihat, bahkan terkadang cenderung tidak bisa konsisten. Dalam hal ini guru harus bisa melakukan rayuan kepada siwa agar siswa kembali pada taraf belajar mereka, beberapa siswa ada yang cenderung menyukai belajar di luar kelas dari pada di dalam kelas. Jadi, guru harus sebisa mungkin mencari cela agar siswa mau untuk belajar. 2) IQ yang cenderung lebih rendah dari pada anak normal, yang mengharuskan guru lebih sabar, serta guru memberikan materi dari yang paling rendah. 3) penembahan media belajar siswa tunanetra seharusnya menjadi catatan, seperti buku pelajaran yang masih diberikan tapi berbentuk buku pelajarn seperti anak normal. Pada kendala ini guru harus terus menjelaskan tetang meterinya, jadi guru menjelaskan dan siswa tunanetra mendengarkan 4) adanya siswa dengan kekurangan ganda, siswa tunanetra juga tunagrahita. Jika masuk pada taraf kekurangan pastinya seorrang guru haruslah tetap mengajarkan semaksimal mungkin kepada siswa.

Keadaan kendala dalam sebuah proses penumbuhan minat membaca siswa tunanetra adalah sebuah keniscayaan, dari beberapa kendala di atas, dalapat di jadikan acuan bahwa dalam optimalisasi guru menumbuhkan minat membaca huruf braille tedapat beberapa kendala baik yang bersifat internal dari guru, dan bersifat eksternal dari pihak pemangku kebijakan. Pada kendala internal guru mempunyai beberapa kendala seperti 1) Siswa tunanetra yang cenderung semangat belajarnya naik-turun, jadi guru harus memberikan motivasi secara terus menerus. 2) IQ masingmasing siswa tunanetra cenderung rendah dari 
pada siswa normal. Disinilah guru harus lebih memperdalam kendala-kendala yang terjadi serta guru harus lebih sabar dalam melakukan proses pembelajaran. Sedangkan pada kendala eksternal adalah 1) masih perlunya penambahan media belajar bagi anak tuanetra, lebih-lebih masuk era digitalisasi para tunanetra seharusnya bisa mengikuti perkembangan yang terjadi. 2) masih belum adanya buku pelajaran dengan mengunakan huruf braille, jadi perlu adanya buku pelajaran dengan huruf braille.

\section{Pembahasan}

Optimaliasi Guru dalam Menumbuhkan Minat Membaca Huruf Braille Siswa Tunanetra

Optimalisasi guru dalam

menumbuhkan minal membaca huruf braille sudah di lakukan oleh para guru tunanetra di Sekolah Luar Biasa Negeri Cerme Gresik (SDLB). Beberapa cara yang dilakukan adalah dengan memperkuat proses pembelajaran mengenal huruf braille, sebagaimana hasil riset Assyifa juga menyebutkan bahwa penumbuhan minat membaca huruf braille pada siswa tunanetra harus di awali dengan proses pra membaca (Assyifa, 2019). Hal tersebut tidak dapat terlepas dengan proses pembelajaran, terutama dalam pengelolaan pembelajaran di mulai dari perencanaan, pelaksanaan sampai pada tahap evaluasi. Karena hanya dengan proses yang baiklah dari diri siswa tunanetra akan tumbuh minat membaca yang baik pula. Mc Charty juga menjelaskan bahwa keberadaan guru sebagai tutor dalam pembelajaran braille sangatlah di perlukan, terlepas banyaknya teknologi yang berkembang, karena teknologi hanya sebagai media dalam proses pembelajaran. Karena keberadaan guru dalam proses pembelajaran sangat mampu menumbuhkan motivasi siswa untuk mengenal huruf braille(McCarthy et al., 2016).

Pada tahapan penumbuhan minat membaca huruf braille yang sudah di lakukan oleh para guru di SDLB Cerme Gresik yaitu dengan mengoptimalkan pembelajaran melalui tiga tahapan. Pertama, tahap perencanaan: para guru di haruskan menyiapkan perangkat pembelajaran secara tepat, mulai dari Rencana Pelaksanaan Pembelajaran yang di dalamnya terdapat model pembelajaran yang tepat pada siswa tunanetra dan media pembelajaran yang di sukai oleh siswa tunanetra. Keberadaan pemilihan perangkat pembelajaran yang tepat juga di sampaikan oleh Lumadi dan Maguvhe, bahwa dalam proses pembelajaran siswa tunanetra, seharusnya guru benar-benar mempunyai komitmen untuk memberikan pembelajaran terbaiknya serta benar-benar meluangkan waktu untuk memberikan proses pembelajaran terbaik di mulai dengan perencanaan pembelajaran (Lumadi \& Maguvhe, 2012) Karena proses pemilihan perencanaan pembelajaran hingga pemilihan media pembelajaran terbaik untuk siswa tunanetra akan berpengaruh sifat dan kualitas dari realitas disiplin ilmu yang nantinya di ajarkan oleh guru, terutama tentang pembelajaran huruf braille. Harimi juga menyampaikan riset tentang keberadaan perencanaan pembelajaran harus di maksimalkan terutama dalam strategi 
pembelajaran yang akan di ajarkan kepada siswa tunanetra. Namun,dalam strategi perlu adanya modifikasi dan inovasi terutama dalam proses belajar membaca. karena di perlukannya sifat sensitif dalam hal perabaan agar terciptanya aksebilitas bagi siswa dalam proses pembelajaran.(Harimi, 2018).

Perencanaan dalam pembelajaran pada siswa tunanetra juga di sampaikan oleh Jumadi, Atmazaki dan Thahar bahwa posisi perencanaan harus dilakukan guru secara maksimal dengan pemilihan media pembelajaran yang tepat terutama media dan model belajar untuk siswa tunanetra dalam menumbuhkan minat membacanya.(Thahar, 2013) sejalan dengan pemaparan Rudiyati tentang pentingnya memaksimalkan perencanaan pembelajaran membaca huruf braille yang tepat. Namun, Rusdiyati menambahkan perlu adanya "reward" bagi siswa yang mengalami kemajuan pada setiap pembelajaran (Rudiyati, 2010). Kemudian pada tahap selanjutnya tinggal bagaimana guru merancang pelaksanaan pembelajaran yang di mulai dari pembuatan Rencana Pelaksanaan Pembelajaran (RPP).

Kedua, tahap pelaksanaan, dalam tahap pelaksanaan pembelajaran, secara maksimal para guru menggunakan memanfaatkan strategi pembelajaran yang di dalamnya terdapat beberapa metode seperti: 1) Metode menghafal untuk siswa tunanetra dalam mengenali huruf abjad, yaitu dengan menghafal abjad dari A-Z dan angka, metode menghafal menjadi kunci pertama bagi siswa tunanetra sebelum mereka belajar meraba.
Karena dengan meghafal siswa akan memahami urutan dari huruf abjad, sehingga memudahkan dalam belajar huruf braille.(Iswara et al., 2013) begitu penting menghafal huruf abjad sebagai kunci pertama sebelum materi selanjutnya, seperti pengenalan titik braille dan media teknologi lainnya (Wibawa \& Rushjayanti, 2019). 2) metode ceramah, dimuali dengan guru memberikan materi dengan bercerita serta menjelaskan secara runtut tentang titik-titik pada huruf braille. Ceramah menjadi salah satu metode yang efektif untuk anak tunanetra, sebagaimana hasil riset Saputri menjelaskan tentang metode ceramah, sebagai salah satu metode pilihan dalam melasanakan pembelajaran siswa tunanetra yang di gunakan guru dalam melasanakan pembelajaran agar siswa dapat memahami secara maksimal.(D. R. Saputri, 2013). 3) Metode tanya jawab, mejadi pilihan para guru untuk mengetahui perkembangan yang terjadi pada siswa tunanetra dalam menghafal kosa abjad dari A sampai Z, metode ini juga di gunakan sebagai bahan untuk mencari hambatan-hambatan yang terjadi dari siswa dalam belajar huruf braille, Saputri, dalam risetnya memberikan pandangan pentingnya metode tanya jawab bagi siswa tunanetra untuk menjalin kedekatan pada siswa, serta menjadikan tolak ukur guru dalam proses pembelajaran huruf braille siswa tunanetra (D. R. Saputri, 2013). 4) Metode latihan, menjadi metode dalam membaca dan menulis yang sering digunakan para guru di SLB Negeri Cerme Gresik, seperti contoh tentang proses awal siswa meraba titik-titik 
pada huruf braille. Setelah siswa mahir membaca, guru berikan materi menulis dengan menggunakan reglet dan stilus (Harimi, 2018) Karena dengan menulis siswa nantinya dapat pelajaran membaca dari yang sudah di tulis, sebagaimana latihan yang sudah di berikan oleh guru. Hal ini juga di sampaikan Harimi tentang strategi yang harus diberikan kepada siswa agar siswa lebih cepat memahami huruf braille yaitu dengan berlatih menulis. (Harimi, 2018) Namun, perlu diperhatikan bahwa pembelajaran menulis pada siswa tunanetra diperlukan beberapa strategi agar siswa tida bosan. 5) Metode demonstrasi digunakan guru kepada siswa untuk di ajarkan menggunakan papan kayu braille agar dapat mengetahui titik-titik (kode) pada setip huruf abjad. Setelah papan kayu braille siswa di berikan pembelajaran tentang braille tekx kasar dan tahap akhir siswa di ajarkan menggunakan braille teks halus. Metode demonstrasi menjadi salah satu metode pilihan sebgaimana Saputri dan Wangid, dari hasil risetnya dijelaskan bahwa dalam memberikan pemebelajaran kepada siswa tunanetra para guru lebih memilih menggunakan metode demonstrasi, dengan tujuan siswa lebih mudah memahami apa yang sudah di kerjakan serta mendorong siswa untuk lebih peka terhadap pembelajaran, terutama huruf braille.(A. E. Saputri et al., 2013)

Tahap ketiga adalah tahap evaluasi pembelajaran untuk siswa tunanetra dalam menumbuhkan minat membaca braille. Fatin dkk. menjelaskan tentang keberadaan evaluasi yang menjadi kunci dalam menjawab sebuah proses yang berjalan, evaluasi juga menjadi tolak ukur atas keberhasilan dari pembelajaran. Karena dari evaluasilah akan ada sebuah proses perbaikan dan pegembangan (Fantin et al., 2016). Pada evaluasi pembelajaran huruf braille guru di SLB Negeri Cerme mempunyai beberapa cara, seperti: guru melakukan observasi secara langsung kepada masing-masing siswa dalam proses pembelajaran memahami huruf braille menggunakan media braille. Selain itu guru melakukan interaksi secara berkala kepada masing-masing siswa, pentingnya interaksi kepada siswa tunanetra juga disampaikan oleh Widyastuti, karena keterbatasan siswa tunanetra. Maka dirasa sangat penting untuk melakukan interaksi secara berkala, mulai dari interaksi satu arah, dua arah sampai pada pola interaksi antar arah (Widyastuti, 20116). Model evaluasi ini perlu di lakukan agar dapat mengetahui perkembangan siswa tunanetra dalam memahami huruf braille ketika membaca (D. R. Saputri, 2013). Selain tahapan evaluasi di atas, guru melakukan evaluasi dengan kartu huruf braille,(Anindita, 2020). Kartu menjadi salah satu alat evaluasi untuk mengetahui sejauh mana siswa sudah memahami tentang huruf braille. Media kartu di gunakan guru dengan memberikan 3 kartu huruf, siswa meraba titik braille pada kartu hurufnya (Anindita, 2020). Sebagaimana hasil penelitian menunjukkan tingkat kepekaan jauh lebih tepat dalam menggunakan kartu huruf.

Media Belajar Guru dalam Menumbuhkan Minat Membaca Siswa Tunanetra 
Berdasarkan dari hasil analisis hasil penelitian maka dapat di ambil sebuah garis lurus, yang menjelaskan beberapa media belajar yang sudah digunakan guru dalam memberikan pelajaran siswa tunanetra pada Sekolah Luar Biasa terfokus Pendidikan Dasar di Cerme Gresik, namun adanya media belajar juga perlu disertai dengan kompetensi guru yang maksimal. Karena menjadikan sukses dalam penumbuhan minat membaca harus di dukung oleh guru, mulai dari motivasi, hambatan dan jalan kesuksesan (Reed \& Curtis, 2011). Pada dasarnya siswa tunanetra selain harus mempunyai pengetahuan yang maksimal pada siswa tunanetra, guru juga di haruskan bertransformasi sebagai mediator pembelajaran pada siswa, sehingga antara guru dan siswa dapat secara optimal mencapau tujuan dari pembelajaran (Lumadi \& Maguvhe, 2012). Para guru tunanetra di Sekolah Luar Biasa Negeri Cerme Gresik dalam proses pembelajaran pada tunanetra menggunakan beberapa media belajar dalam proses menumbuhkan minat membaca siswa tunanetra.

Pertama, dalam hal menghafal huruf braille media yang digunakan oleh guru adalah media audio box sebagai salah satu media yang digunakan siswa di dalam kelas, karena proses pengenalan huruf selain dengan meraba siswa tunanetra dapat menggunakan rekaman huruf-huruf abjad. dan pemanfaatan media sosial whatsapp untuk mengirimkan recorder abjad. Pemanfaatan media sosial menjadi kunci pengembangan di era teknologi khususnya pada siswa tunanetra, meskipun secara jasmani mereka tergolong berkebutuhan khusus, namun secara atura mereka mempunyai hak yang sama dalam mengembangkan pengetahuan. Salah satu riset dari Ramos menjelaskan tentang pentingnya siswa dengan kebutuhan khusus yaitu siswa tunanetra untuk di kenalkan dengan teknologi sebagai alat bantu dan praktik integrasi antara teknologi dan pendidikan. Maka adanya teknologi seperti handphone, (Hope, 2018), (Wibawa \& Rushjayanti, 2019) dan aplikasi WhatsApp menjadi bagian dari media yang dapat dimaksimalkan dalam pembelajaran siswa tunanetra (Ramos \& de Andrade, 2016).

Kedua, media yang digunakan dalam mengasah hafalan siswa tunanetra, yaitu dengan mengguanakan papan braille, setelah faham beralih ke papan braille kasar, setelah siswa faham titik secara lancar maka siswa diberikan materi braille tex, selain media di atas guru juga merangsang otak siswa agar minat membacanya tumbuh yaitu dengan menggunakan media, seperti majalah braille, yang menjadi salah satu solusi agar siswa mempunyai minat belajar braille serta memupuk pengetahuan siswa, Bormans menjelaskan bahwa keadaan majalah atau koran yang di dalamnya terdapat informasi, akan lebih memberikan motivasi pada siswa dalam belajar membaca huruf braille secara berkala, media ini digunakan di belahan negara belgia mulai tahun 1993 sampai saat ini (Bormans, 1993), media cerita dongeng braille, menjadi salah satu media pilihan dalam merangsang pengetahuan siswa dalam membaca dan mengenal dongeng-dongeng 
dalam budaya indonesia, media peta braille, menjadi media informasi yang harus diketahui oleh siswa tunanetra, sebagaimana Dursin dalam riset di negara Turki, menjelaskan bahwa posisi peta sebagai materi yang sangat informatif pada siswa tunanetra, karena dengan peta braille siswa tunanetra akan mengetahui keberadaan tempat tinggal, kota dan negara dimana siswa tinggal. (Dursin, 2012), globe braille dan buku pelajaran (masih belum braille) keberadaan buku braille menjadi media yang sangat yang efektif dalam mendukung siswa mengenal huruf braille, sebagaimana buku bangka yang di gunakan para guru di Banglades sebagai support awal siswa dalam belajar huruf braille, selain mudah dalam menghafal titik braille siswa akan terbiasa membaca secara bertahap (Sojib \& Zafar Iqbal, 2018).

Ketiga, media pendukung membaca selanjutnya adalah media reglet, sebagai salah satu media untuk meningkatkan kepekaan siswa dalam menulis huruf braille,(Listyaningtyas, n.d.) stilus dan kertas tebal, media ini digunakan untuk menulis awal siswa.(Rudiyati, 2010) Menulis menjadi salah satu pilihan untuk meningkatkan minat membaca huruf braille pada siswa tunanetra, Rahma Dia menjelaskan bahwa menulis akan menjadi pengingat siswa dalam mengenal huruf braille. Namun, yang menjadi catatan adalah pembelajaran menulis siswa harus dimulai dari tulisan-tulisan singkat (Dia, 2012). karena dari tulisan inilah siswa akan belajar membaca perhuruf, perkata hingga perkalimat.

\section{Kendala Guru dalam Menumbuhkan Minat Membaca Huruf Baraille Siswa Tunanetra} Selain proses menumbuhkan minat membaca huruf braille siswa tunanetra yang secara keseluruhan cukup efektif, namun tidak menutup kemungkinan adanya beberapa kendala di dalamnya, hal ini juga terjadi di Sekolah Luar Biasa Negeri Cerme Gresik dalam optimalisasi guru menumbuhkan minat membaca huruf braille didapati beberapa kendala baik yang bersifat internal dari guru dan bersifat eksternal dari pihak pemangku kebijakan. Karena kebijakan dari berbagai pihak terutama pemerintah sangatlah dibutuhkan sebagaimana kebijakan di Negara Belgia (Bormans, 1993). Adapun kendala internal yang di alami guru pada Sekolah dasar Negeri Cerme Gresik adalah, sebagai berikut: 1) Siswa tunanetra yang cenderung semangat belajarnya naik-turun. Solusi yang diambil oleh para guru adalah harus memberikan motivasi secara terus menerus. Hal ini juga menjadi catata akhir dari penelitian Maguvhe bahwa keberadaan guru menjadi kunci dalam memberikan dorongan motivasi pada siswa tunenetra. Dari motivasi inilah siswa akan lebih berminat dalam memahami pelajaran yang di ajarkan oleh guru, terutama dalam penumbuhan minat membaca huruf braille pada tunanetra (Lumadi \& Maguvhe, 2012). 2) IQ masing-masing siswa tunanetra cenderung rendah dari pada siswa normal. Disinilah guru harus lebih memperdalam kendala-kendala yang terjadi pada siswa tunanetra, karena keterbatasan yang di alaminya, terkadang menjadikan mereka depresi hingga tidak ingin 
mengenal pengetahuan lebih luas (Nuraeni et al., 2018). Namun secara berkala guru harus sabar dalam melakukan proses pembelajaran yang diberikan kepada siswa tunanetra, sehingga mereka menemukan kepercayaan diri hingga mereka termotivasi untuk mempelajari pengetahuan secara luas. Sedangkan pada kendala eksternal yang di alami guru dalam proses penumbuhan minat membaca huruf braille siswa tunanetra adalah: 1) masih kurangnya media pembelajaran maka perlu adanya penambahan media belajar bagi anak tuanetra, lebih-lebih masuk era digitalisasi para tunanetra seharusnya bisa mengikuti perkembangan yang terjadi. Sebagaimana beberapa media teknologi yang berkembang pada siswa tunenetra mulai dari braille book berbasis devive, (Sojib \& Zafar Iqbal, 2018), balok braille berbasis PCA, (Park \& Shin, 2012), aplikasi pengenalan suara, (Iswara et al., 2013), keyboard braille, (Nanda et al., n.d.), Tabel Priodik (Wardhani \& Suprihatiningrum, 2015) dan beberapa media berbantu smart phone lainnya (Hope, 2018). 2) Kurang adanya pelatihan dalam meningkatkan kompetensi guru tunanetra, hal ini menjadi catatan pada hasil riset Fitra dan Iswari bahwa pada dasarnya guru di sekolah luar biasa mempunyai kewajiban untuk terus meningkatkan kompetensi yang di milikinya, hal tersebut harus di dukung oleh berbagai pihak, terutama sekolah dan pemerintah daerah, selain motivasi pada diri guru (Fitra \& Iswari, 2019). Hal ini diperkuat oleh wati tentang perlunya memperkuat kompetensi guru agar pembelajaran dapat berjalan secara maksimal (Wati, 2014). 3) masih belum adanya buku pelajaran dengan mengunakan huruf braille, menjadi salah satu masukan agar adanya buku pelajaran dengan huruf braille. Agar nantinya dapat memacu semangat siswa dalam membaca dan memperluas pengetahuannya.

\section{SIMPULAN}

Berdasarkan beberapa hasil pembahasan di atas, maka dapat di ambil kesimpulan tentang beberapa proses penumbuhan minat membaca huruf braille, yang sudah di lakukan oleh Sekolah Luar Biasa Negeri Cerme Gresik, yaitu dengan memperkuat adanya proses pembelajaran huruf braille, meliputi: Pertama, perencanaan dari guru meliputi pembuatan Rencana Pelaksanaan Pembelajaran yang di dalamnya erdiri dari strategi guru, metode, dan cara mengevaluasinya. Kedua, Pelaksanaan pembelajaran yaitu guru memaksimalan pemilihan strategi pembelajaran yang tepat, muulai dari metode, model hingga media belajar siswa tunanetra. Ketiga, tahap Evaluasi yang dilakukan guru dalam menganalisa proses dan hasil belajar siswa tunanetra. Selain itu tahapan pemaanfaatna media belajar menjadi sebuah keharusan oleh guru, beberapa media belajar yang digunakan guru dalam menumbuhkan minat membaca huruf braille, seperi audio box, braille tex, braille kasar, braille halus, majalah braille, peta braille dan beberapa media lainnya. Namun, keadaan proses pembelajaran di atas, tidak menutup kemungkinan adanya sebuah kendala, sebagaimana beberapa kendala yang dialami 
oleh guru Sekolah Luar Biasa Cerme Gresik dalam penumbuhan minat membaca huruf braille, seperti naik turunya motivasi pada diri siswa, IQ siswa tunanetra yang cenderung rendah dari pada siswa normal, perlunya peningkatan kompetensi pada guru tunanetra, serta perlu adanya media pembelajaran yang sesuai kebutuhan siswa, seperti buku pelajaran braille.

\section{DAFTAR RUJUKAN}

Ali, M. (2009). Pendidikan Untuk Membangun Nasional. Grasindo.

Anindita, A. A. (2020). Pembelajaran Braille Bermedia Flashcard Di Tklb Tunanetra. Jurnal Pendidikan Khusus, l(1), 1-5.

Arif, M., \& Kalimatusyaro, M. (2020). Revitalisasi Pendidikan Ruhani Dalam Rangka Mencegah Penyalahgunaan Narkoba Pada Pelajar. TARBAWY: Indonesian Journal of Islamic Education, 7(1), 41-55. https://doi.org/10.17509/t.v7i1.23800

Arif, M., \& Sulistianah, S. (2019). Problems in 2013 Curriculum Implementation for Classroom Teachers in Madrasah Ibtidaiyah. Al Ibtida: Jurnal Pendidikan Guru MI, 6(1), 110. https://doi.org/10.24235/al.ibtida.snj.v $6 \mathrm{i} 1.3916$

Assyifa, A. F. (2019). Pembelajaran Pra Membaca Braille Pada Siswa Tunanetra Kelas I Sekolah Dasar Di SLB Negeri 1 Bantul. Jurnal Widia Ortodidaktika, 8(5), 439-448.

Bormans, G. (1993). Flemish daily newspaper in braille. British Journal of Visual Impairment, 11(2), 66-67. https://doi.org/10.1177/026461969301 100208

Chiu, T. (2014). Braille, amma and integration: The hybrid evolution of education for the blind in Taiwan, 1870s-1970s. Paedagogica Historica, 50(1-2),

182-194. https://doi.org/10.1080/00309230.201 3.874362

Daftar Sekolah Luar Biasa (SLB) Recommended di Gresik. (2017, December 23). http://datasekolah.net/daftar-sekolahluar-biasa-slb-recommended-di-gresik/

Darlis, A. (2017). Hakikat Pendidikan Islam: Telaah Antara Hubungan Pendidikan Informal, Non Formal dan Formal. Jurnal Tarbiyah, 24(1), 84-103.

Dia, E. R. (2012). Efektifitas Penggunaan Tulisan Singkat Braille Dalam Meningkatkan Kecepatan Menulis Bagi Anak Tunanetra. 1, 12.

Dursin, A. G. (2012). Information Design and Education for Visually Impaired and Blind People. Procedia - Social and Behavioral Sciences, 46, 5568-5572. https://doi.org/10.1016/j.sbspro.2012.0 6.477

Fantin, D., Sutton, M., Daumann, L. J., \& Fischer, K. F. (2016). Evaluation of Existing and New Periodic Tables of the Elements for the Chemistry Education of Blind Students. Journal of Chemical Education, 93(6), 10391048.

https://doi.org/10.1021/acs.jchemed.5b 00636

Fitra, R. R., \& Iswari, M. (2019). Profil Guru Penyandang Tunanetra (is) Berprestasi Di Cabang Olahraga Catur Tingkat Asia Tenggara. JUPPEKhu: Jurnal Penelitian Pendidikan Khusus, 7(2), 1-6.

Harimi, A. C. (2018). Strategi Pembelajaran Kemahiran Menulis Bagi Peserta Didik Tunanetra. Prosiding Konferensi Bahasa Arab IV Universitas Negeri Malang, 51-56.

Hope, J. (2018). Educate blind, low-vision students about accessibility features of the iPhone, iPad. Disability Compliance for Higher Education, 23(7), 2-2. https://doi.org/10.1002/dhe.30388

Hoshino, T., Kiyosawa, T., Otake, T., \& Yonezawa, Y. (2000). Basic study of optimum stimulus mode for finger 
Braille display. Electronics and Communications in Japan, 83(6), 8.

Isnaini, B. (2013). Meningkatkan Kemampuan Membaca Permulaan Tulisan Braille Melalui Sistem Menggold Bagi Anak Tunanetra. E-JUPEKhu (Jurnal Ilmiah Pendidikah Khusus), 1(1), 22-32.

Iswara, A. M., Sumpeno, S., Purnomo, M. H., \& Hakim, J. A. R. (2013). Aplikasi Pengenalan Kata Pada Huruf Braille dan Pelafalannya. Jurnal Teknik Pomits, 2(2), 335-340.

Listyaningtyas, R. (n.d.). Pembelajaran Menulis Braille Dengan Reglet Pada Anak Tunanetra Kelas I SD Di SLBN A Bandung. 9.

Lumadi, M. W., \& Maguvhe, M. O. (2012). Teaching Life Sciences to Blind and Visually Impaired Learners: Issues to Consider For Effective Learning Mediation Practice. The Anthropologist, 14(5), 375-381. https://doi.org/10.1080/09720073.201 2.11891260

McCarthy, T., Rosenblum, L. P., Johnson, B. G., Dittel, J., \& Kearns, D. M. (2016). An Artificial Intelligence Tutor: A Supplementary Tool for Teaching and Practicing Braille. Journal of Visual Impairment \& Blindness, 110(5), 309322.

https://doi.org/10.1177/0145482X161 1000503

Nanda, A. S. A., Anisa, M., \& Mulatsih, W. T. (n.d.). Keyboard Braille Dengan Output Suara Sebagai Alat Pembelajaran Untuk Penyandang Tunanetra. 4.

Nuraeni, P., Rusdiyani, M.Pd, Dr. Hj. I., \& Listiyaningtyas, M.Pd, R. (2018). Influence of Use of Media Number Concept Tunanetra Ability to Read Braille Numbers. UNIK (Jurnal Ilmiah Pendidikan Luar Biasa), 3(2). https://doi.org/10.30870/unik.v3i2.530 9

Park, S.-J., \& Shin, D. (2012). PCA-based image recognition of braille blocks for guiding the visually handicapped. International Journal of Precision Engineering and Manufacturing,
13(12),

2115-2120.

https://doi.org/10.1007/s12541-012-

0280-3

Peringkat pendidikan Indonesia di bawah Malaysia, China yang terbaik di dunia. (2019, December 4). BBC News Indonesia. https://www.bbc.com/indonesia/majal ah-50648395

Ramos, S. I. M., \& de Andrade, A. M. V. (2016). ICT in Portuguese reference schools for the education of blind and partially sighted students. Education and Information Technologies, 21(3), 625-641. https://doi.org/10.1007/s10639-0149344-6

Reed, M., \& Curtis, K. (2011). High School Teachers' Perspectives on Supporting Students with Visual Impairments toward Higher Education: Access, Barriers, and Success. Journal of Visual Impairment \& Blindness, 105(9), 548-559. https://doi.org/10.1177/0145482X111 0500906

Rudiyati, S. (2010). Pembelajaran Membaca dan Menulis Braille Permulaan pada Anak Tunanetra. Jassi Anakku, 9(1), 57-65.

Saputri, A. E., Wangid, M. N., \& Uny, Pp. (2013). Pembelajaran Sains Sd Untuk Siswa Tunanetra Di Slb-a Yaketunis. Jurnal Prima Edukasia, 1(2), 124134.

Saputri, D. R. (2013). Proses Pembelajaran Seni Musik Bagi Siswa Tunanetra. Harmonia, 13(1), 37-44.

Sojib, N., \& Zafar Iqbal, M. (2018). Single Cell Bangla Braille Book Reader for Visually Impaired People. 2018 International Conference on Bangla Speech and Language Processing (ICBSLP), 1-4. https://doi.org/10.1109/ICBSLP.2018. 8554607

Suderajat, S., Bidari, R. A. A., \& Amallia, M. (2018). Implementasi Pendidikan Inklusi Di SD Muhammadiyah 3 Cirebon. Jurnal Hadhariyah, 4(1), 113-138. 
Thahar, H. E. (2013). PENINGKATAN KECEPATAN EFEKTIF MEMBACA TULISAN BRAILLE DENGAN TEKNIK DUA TANGAN BAGI TUNANETRA KELAS V SLB NEGERI 2 PADANG. 1, 11.

Wardhani, N. S., \& Suprihatiningrum, J. (2015). Proses Pengembangan Tabel Periodik Unsur (TPU) Braille untuk Siswa Difabel Netra. INKLUSI, 2(1), 125.

https://doi.org/10.14421/ijds.020106

Wati, E. (2014). Manajemen Pendidikan Inklusi Di Sekolah Dasar Negeri 32 Kota Banda Aceh. Jurnal Ilmiah Didaktika, 14(2), 368-378. https://doi.org/10.22373/jid.v14i2.508

Wibawa, K. S., \& Rushjayanti, K. D. K. D. (2019). Implementation of Electronic Braille Alphabet Connected with Android Smartphone Device. International Journal of Computer Engineering and Information Technology, 11(12), 268-272.

Widyastuti, R. (20116). Pola Interaksi Guru dan Siswa Tunanetra SMPLB A Bina Insani Bandar Lampung. Al-Jabar: Jurnal Pendidikan Matematika, 7(2), 257-266. 